\title{
Application and Validation of a Model for Measuring the Perceived Quality of Health Services in Medical Tourism
}

\author{
Espinoza $\mathrm{MG}^{1}$, Gonzalez JG${ }^{2 *}$, Saldiar Gonzalez $\mathrm{SJ}^{3}$ and Munoz del Real $\mathrm{G}^{3}$ \\ ${ }^{1}$ Universidad Autonoma de Baja California, Mexico \\ ${ }^{2}$ Universidad Autónoma de Nuevo Leon, Mexico \\ ${ }^{3}$ Universidad Autónoma de Baja California, Mexico
}

*Corresponding author: Janet Garcia Gonzalez, Universidad Autónoma de Nuevo León, Address 5o Avenida No 404 Col. Guerra, Guadalupe, Nuevo León, México, Tel:+5212759309;

Email: janetgarcia71@yahoo.com.mx; janet.garciagnz@uanl.edu.mx

\section{Research Article}

Volume 4 Issue 3

Received Date: April 14, 2021

Published Date: May 05, 2021

DOI: $10.23880 /$ jqhe- 16000222

\section{Abstract}

Medical tourism destinations do not have solid data to identify the quality of health services, for this reason, this research aims to validate the Servperf Model instrument in the context of medical tourism health services and make this a verifiable and valid tool to measure the perceptions of the service received, that serves as an alternative to generating information and allowing companies to be more competitive and to increase the inflow of tourism. We analyzed the variables of tangibility, reliability, responsibility, safety and empathy, to identify which affect the perception of quality, through factor analysis it was possible to determine if there is a correlation between the variables that affect the perception of quality of service and which variables are the most representative in the medical tourism environment. The results of the factorial analysis through the principal components extraction method, allowed determining if there is a correlation between the variables that affect the perception of service quality and that the variables of reliability and empathy are the most representative in the medical tourism environment. The effects that can be observed not addressing these problems are client decrease, reduction in perceived quality and a decrease in the recommendation rate.

Keywords: Tourism; Medical Tourism; Quality; Services; Servperf Model

\section{Introduction}

Nowadays, a significant amount of tourists seek medical attention abroad, demanding better medical attention and medical service benefits, they also demand that hospitals and medical clinics offer a certain degree of reliability in their medical personnel, medical staff and medical treatment. In more modern times, there has been a great deal of interest in creating therapeutic spaces [1].

A positive perception of the quality service given by the medical facility can have positive consequences in terms of loyalty and personal relations with the client or customer in the long run and as a consequence encourage the medical businessman to constantly improve quality services in their medical facilities, and that is the primary objective of this document.

The growth of global medical tourism is driven by the participation of various developing countries such as Thailand, Taiwan, Singapore, Malaysia, Costa Rica, Mexico, Turkey, and India [2]. Medical Tourism can be defined as the process of traveling outside the country of residence for the purpose of receiving medical care. There's a variety of medical 
tourism destinations that don't have solid data regarding the quality of health services that allow us to identify the quality of health services, therefore arises the necessity to develop measurement schemes to allow the organizations in the tourism sector to monitor and trace relevance indicators, enabling the user to obtain plenty satisfaction of its needs and therefore acquire elements to maximize the offer of this economic sector.

For this reason, the purpose of this document is to validate a measurement instrument as a verifiable and valid tool to measure the perception of medical services granted in a touristic environment. For that, the Servpef measurement model instrument (Service Performance) was adopted, proposed by Cronin, et al. [3], and analyzed the tangibility, reliability, responsibility, security, and empathy variables.

Validating the Servpef measurement model as a tool means finding an effective application that works as a way of measuring the medical service customer's reaction and how the customer perceives the performance given by the medical facility and in this manner, these could possess information and tools that will enable medical facilities to make decisions to make customers have better and more positive perceptions of their medical service granted.

\section{Theoretical Framework}

Previously, hospitals were evaluating health care services provided to patients based on the opinions of medical, administrative and technical staff. Nowadays, this point of view has been shifted to be based on the opinions of services beneficiaries [4].

The concept of quality has evolved from ancient times to the present day, the new demands that are associated with the quality management require changes in the mentality and cultural organization that adequates to every company. The word quality can be interpreted in many different ways; each interpretation can differ from one another by the level of satisfaction or conformity from the customer. Quality is very subjective, and if you ask a broad range of clinicians, patients or hospital administrators you will probably receive a variety of responses [5].

Zeithaml, et al. [6] defines quality as the superiority or excellence; the perceived quality can be defined as the consumer's judgment about total excellence or superiority of a product or a service [6]. Crosby states that quality goes in accordance with the requirements and these need to be clearly established to avoid any misunderstandings; the measures need to be taken continuously to be in accordance with the requirements; failing to detect nonconformity can be defined as a lack of quality [7]. When research related to quality is carried out, it's almost impossible not to mention customer satisfaction, because these are closely related concepts; service quality is a precedent of service satisfaction. According to Thompson, "currently achieving full customer satisfaction is an essential requirement to earn a place in the mind of customers and therefore, in the target market" [8]. Therefore, it can be considered that customer satisfaction is the result of offering goods and services that meet or exceed needs and is known as "expected quality", and of course it is what the customer assumes that should receive.

On the other hand, Medina warns that a satisfied customer tells four or six people about his experience and a dissatisfied customer will tell nine or fifteen people about his experience. $96 \%$ of dissatisfied customers do not complain, however $91 \%$ of these simply decide to leave and never come back on the other hand [9]. Kotler, et al. [10] mention that quality is linked with the valor and client satisfaction, and they also define quality as the totality of aspects and characteristics of a product or service that relate with its ability to satisfy the client needs. They also mention that quality goes beyond the concept of quality or having defects; it starts with the client needs and ends with client satisfaction.

Due to the service subjectivity, it's hard to determine the quality levels and their impact on the results, a significant portion of the decisions made by directives regarding service quality are based on intuition. To achieve better results and being able to determine the impact that these make, the application of measurement tools plays a very important role in achieving better results.

There are quality models that have a direct relationship with health services, one of them is the Donabedian healthcare model [11] that makes reference to medical services the Kano, et al. [12] is considered to be a very useful tool for quality management and client satisfaction. The Servqual de Zeithmal, et al. [13], is also considered to be a major contribution in measuring functional quality for a wide range of services like healthcare among them, and for last, the Gronroos, et al. [14] relates quality with the corporate image. The Servperf model implemented by Cronin, et al. [3], talks about the exclusive attention given to the evaluation of the performance for measuring and evaluating the quality service, it is important to mention that the methodology used by the Servpef model has the same items and dimensions as the Servqual model, the only difference between them is that the Servqual model takes away the part referring the clients expectations.

The Servperf model solely utilizes the perception as a good approximation to the client's satisfaction, which can be defined as "the level of the person's state of mind that results in comparing the perceived performance of a product or a 
service with its expectations" [15].

It's important to mention that the contributions from Zeithaml, et al. [6] that validated the Servqual model, made the model as the most diffused and applicable to measuring quality services; however, Cronin and Taylor founders of the Servperf model came to the conclusion that Zeithaml, et al. [6] model founders of the Seroquel model is not the best suited or adequate to evaluate the service quality. Servpef model is related to problems of interpretation in the concept of expectation, the variability of service benefits, and the perceptions of the service given. According to Cronin, et al. [3], some empirical evidence indicates that the perception of the performance by itself can predict individual behavior.

In this manner, Cronin and Taylor proposed an alternative model named Servperf, composed of 22 items from the Seroquel model that are used exclusively to measure service perceptions. Thus, the quality of the service will be higher, the greater the sum of these perceptions.

In this document, the Servperf model was chosen for the following reasons: the interviewer needs less time to answer the questionnaire because he's only going to be asked about the item once; the interpretation and analysis tasks will be easier to complete.

\section{Methodology}

To carry out the objective of the study, it was designed an investigation with a quantitative approach of the field and documental type. Gathering up data was done through the standardized questionnaire of 22 item of the Servpef model. It's also important to mention that this study was implemented in the medical district in the city of Mexicali, Baja California, Mexico, which is considered as one of the main medical tourism destinations in the state of Baja California.

Probabilistic sampling by clusters or conglomerates was used in this study that consisted in selecting hospital establishments and specialized medical centers where it was possible to carry out with the study within the medical district in the city of Mexicali. It's important to mention that the hospital establishments and specialized medical centers that were chosen for this investigation because of their high number of medical specialties and a high number of patients. Prior to this study, the size of the sample was taken by means of a simple random sampling system, for an infinite universe, whose formula is:

$$
n=\frac{\sigma^{2} p q}{e^{2}}
$$

Where

$\sigma^{\wedge} 2=$ degree of confidence with which one will work $(1,654)$ and that is equivalent to $90 \%$ of the cases.

$\mathrm{p}=$ Chance of success, in this case, it is $50 \%$.

$\mathrm{q}=$ Probability of failure; that is the complement of the probability in favor of $50 \%$, so when adding both probabilities it is $100 \%$. It is the value that broadens the sample to better allow the detection of the behavior in the traits of greater variation.

$\mathrm{e}=$ Maximum permissible error, in this case, it is $6 \%$.

The value obtained from $\mathrm{n}$ indicates that 188 medical tourists need to be surveyed. At the end of the survey period, a total of 195 surveys were applied (Table 1).

\begin{tabular}{|c|c|c|}
\hline Concept & Description & No. of interviews \\
\hline \multirow{2}{*}{$\begin{array}{c}\text { Testing of } \\
\text { measuring } \\
\text { device }\end{array}$} & Institutions: & 81 \\
\cline { 2 - 3 } & $\begin{array}{c}\text { 1 Hospital } \\
\text { 2 Specialized } \\
\text { medical centers }\end{array}$ & 114 \\
\hline
\end{tabular}

Source: Author's own elaboration.

Table 1: Applying measuring device.

\section{Validation of Measuring Instrument}

Validation of the instrument is probably the most important, especially from a scientific perspective, and refers to how successfully an instrument represents and measures a theoretical concept. For this reason, the instrument was subjected to validity and reliability tests of Cronbach's Alpha, which measures the homogeneity of the questions by averaging all the correlations between all the items to see that they effectively resemble with each other. its interpretation, it is considered that the closer the index is to end 1 , the better the reliability (100\%), considering an acceptable result from 0.70 (Table 2).

\begin{tabular}{|c|c|}
\hline Range & Magnitude \\
\hline $0.81-1.00$ & Very High \\
\hline $0.61-0.80$ & High \\
\hline $0.41-0.60$ & Moderate \\
\hline $0.21-.040$ & Low \\
\hline $.0001-0.20$ & Very Low \\
\hline
\end{tabular}

Source: author's own elaboration, based on Cronbach's Alpha coefficient.

Table 2: Calculation values of Cronbach's Alpha coefficient.

The analysis of the Pearson correlation coefficient was carried out, which describes the strength of the relationship 
between two sets of variables on an interval scale, that is, the index that measures the degree of covariation between different linearly related variables.

For this study, the correlation between the variables is the dependent variable "quality of service" and the five independent variables, intangibility, reliability, responsibility, security and empathy.

The Kaiser-Mayer-Olkin sample adequacy test (KMO coefficient) was performed, which contrasts if the partial correlations between the variables are small, it takes values between 0 and 1 , and it indicates that the factorial analysis is more adequate as higher its value is (Table 3 ).

\begin{tabular}{|c|c|}
\hline Indicator & Value \\
\hline $1,00 \mathrm{KMO}>0,90$ & Excellent sampling adaptation. \\
\hline $0,90 \mathrm{KMO}>0,80$ & Good sampling adaption \\
\hline $0,80 \mathrm{KMO}>0,70$ & Acceptable sampling adaptation. \\
\hline $0,70 \mathrm{KMO}>0,60$ & Regular sampling adaptation \\
\hline $0,60 \mathrm{KMO}>0,50$ & Bad sampling adaptation. \\
\hline $0,00 \mathrm{KMO} \leq 0,50$ & Unacceptable sampling adaptation. \\
\hline
\end{tabular}

Source: author's own elaboration based on coeficiente (KMO).

Table 3: Coefficient scores Kaiser Meyer Olkin (KMO).

Another test that was submitted to the measuring instrument was the Bartlett sphericity test that allowed establishing that the data comes from a normal multivariate distribution; the Bartlett statistic is roughly distributed according to the chi-square probability model and is a transformation of the determinant of the correlation matrix. If the critical level (Sig.) is greater than 0.05, it cannot reject the sphericity test and, consequently, it cannot assured that the factorial model is adequate to explain the data.

Finally, the ANOVA test was performed to detect significant differences in perceived quality according to the characteristics of the respondents.

\section{Results}

The composed reliability was performed and a Cronbach's Alpha of .917 was determined, which means that the instrument used is acceptable and therefore reliable, likewise indicates that it has a high degree of reliability, validated its use for the collection of data, so the analysis of the Pearson correlation for the dependent variable "quality of service" was performed with each of the five dimensions.
The Pearson correlation coefficient is significant at the 0.01 level, showing a perfect positive correlation, which indicates that there is a perfect and positive correlation between variables; in other words, the elements that make up each of the quality dimensions evaluated contribute to the general evaluation of the quality of the service, which can be considered as good.

A Kaiser - Meyer Olkin suitability test (KMO coefficient) was also performed, which contrasts if the partial correlations between the variables are small, takes values between 0 and 1, and indicates that the factorial analysis is more appropriate as higher be its value The adaptation test of Kaiser - Meyer Olkin gave a result very close to $1(.851)$, giving a value of good sample adequacy, with which it can be said that the variables are well explained through the extracted components.

According to the correlation matrix, there is a high level of correlation between all 22 variables studied, making them candidates to be summarized by means of a factorial analysis. Another test that was submitted to the measuring instrument was Bartlett's test of sphericity. It can be verified that the results in the degree of significance obtained in the Bartlett test is less than 0.05, therefore, it is considered valid (Table 4).

\begin{tabular}{|c|c|}
\hline \multicolumn{1}{|c|}{ Indicator } & Value \\
\hline $\begin{array}{c}\text { Sampling adaptation measure Kaiser - Meyer - } \\
\text { Olkin }\end{array}$ & 0.851 \\
\hline Bartlett's sphericity test \\
\hline Chi-square & 1666.8 \\
\hline Degrees of freedom & 231 \\
\hline Significance & 0 \\
\hline
\end{tabular}

Source: author's own elaboration, based on the data collected and processed in the statistical program SPSS, $v 18$. Table 4: Results of the KMO and Bartlett tests.

Following the previous analysis, the ANOVA test was performed to detect significant differences in the perceived quality according to the characteristics of the respondents, which resulted in a very similar level of customer satisfaction regardless of gender, age, source of income, availability of medical insurance or frequency of visit, only in the case of the reason for the visit, it was found that customers who went to the medical district of Mexicali seeking quality medical services showed a higher level of perceived quality, that those who made a visit looking for low costs in their treatments; which indicates that the level of satisfaction is high among customers who come in search of quality service. 
Finally, the principal component extraction method was used to determine a latent component within the established variables, capable of eliminating (or minimizing) the parallel variation between the reagents.
The quality of the service provided by health services in medical tourism, according to the factorial analysis of the main components, is based on five dimensions that represent $32 \%$ of the total variance explained, as shown in Table 5 .

\begin{tabular}{|c|c|c|c|c|c|c|c|}
\hline \multirow{3}{*}{$\begin{array}{c}\text { Component } \\
1\end{array}$} & \multicolumn{3}{|c|}{ Initial solution } & \multicolumn{4}{|c|}{ Extraction } \\
\hline & \multirow{2}{*}{$\begin{array}{c}\begin{array}{c}\text { Eigen initial } \\
\text { value }\end{array} \\
7.143\end{array}$} & \multicolumn{2}{|c|}{$\%$ de variance } & \multirow{2}{*}{$\begin{array}{c}\text { \% accumulated } \\
7.143\end{array}$} & \multirow[t]{2}{*}{$\begin{array}{l}\text { Eigen initial } \\
\text { value }\end{array}$} & \multirow{2}{*}{$\begin{array}{c}\begin{array}{c}\% \text { the } \\
\text { variance }\end{array} \\
32.47\end{array}$} & \multirow[t]{2}{*}{$\%$ accumulated } \\
\hline & & 32.47 & 32.47 & & & & \\
\hline 2 & 1.657 & 7.53 & 40.001 & & & & \\
\hline 3 & 1.52 & 6.909 & 46.91 & & & & \\
\hline 4 & 1.351 & 6.139 & 53.049 & & & & \\
\hline 5 & 1.159 & 5.267 & 58.315 & & & & \\
\hline 6 & 1.052 & 4.783 & 63.098 & & & & \\
\hline 7 & 1.007 & 4.577 & 67.675 & & & & \\
\hline 8 & 0.91 & 4.135 & 71.809 & & & & \\
\hline 9 & 0.778 & 3.536 & 75.345 & & & & \\
\hline 10 & 0.712 & 3.237 & 78.582 & & & & \\
\hline 11 & 0.588 & 2.672 & 81.254 & & & & \\
\hline 12 & 0.571 & 2.596 & 83.85 & & & & \\
\hline 13 & 0.535 & 2.431 & 86.281 & & & & \\
\hline 14 & 0.507 & 2.303 & 88.583 & & & & \\
\hline 15 & 0.414 & 1.884 & 90.467 & & & & \\
\hline 16 & 0.38 & 1.729 & 92.197 & & & & \\
\hline 17 & 0.354 & 1.608 & 93.805 & & & & \\
\hline 18 & 0.323 & 1.469 & 95.274 & & & & \\
\hline 19 & 0.301 & 1.367 & 96.641 & & & & \\
\hline 20 & 0.268 & 1.22 & 97.862 & & & & \\
\hline 21 & 0.245 & 1.114 & 98.976 & & & & \\
\hline 22 & 0.225 & 1.024 & 100 & & & & \\
\hline
\end{tabular}

Source: author's own elaboration from the results obtained and processed in the statistical program SPSS, v21.

Table 5: Total variance explained.

Following the previous analysis, the variables of tangibility, reliability, responsibility, safety and empathy were analyzed, in order to identify which ones affected the perception of quality, through factorial analysis was possible to determine if there is a correlation between the variables that affect the perception of quality, the quality of the service and which variables are the most representative in the medical tourism environment.

With the extracted component, a perceived quality index could be elaborated and it was determined that the variables of reliability and empathy are those that have the highest percentage $24 \%$ and $23 \%$ respectively and can be considered more representative for medical tourists (Table 6). 


\begin{tabular}{|c|c|c|c|c|c|}
\hline Reagent & Component & Punctuation & Percent weight & Dimension & Percent weight of the dimension \\
\hline R18 & 0.485 & 0.068 & $4 \%$ & \multirow{4}{*}{ tangibility } & \multirow{4}{*}{$15 \%$} \\
\hline R19 & 0.612 & 0.086 & $5 \%$ & & \\
\hline $\mathrm{R} 20$ & 0.489 & 0.068 & $4 \%$ & & \\
\hline $\mathrm{R} 21$ & 0.307 & 0.043 & $2 \%$ & & \\
\hline $\mathrm{R} 22$ & 0.655 & 0.092 & $5 \%$ & \multirow{5}{*}{ reliability } & \multirow{5}{*}{$24 \%$} \\
\hline $\mathrm{R} 23$ & 0.561 & 0.079 & $5 \%$ & & \\
\hline $\mathrm{R} 24$ & 0.493 & 0.069 & $4 \%$ & & \\
\hline $\mathrm{R} 25$ & 0.622 & 0.087 & $5 \%$ & & \\
\hline $\mathrm{R} 26$ & 0.691 & 0.097 & $6 \%$ & & \\
\hline $\mathrm{R} 27$ & 0.597 & 0.084 & $5 \%$ & \multirow{4}{*}{ responsibility } & \multirow{4}{*}{$19 \%$} \\
\hline $\mathrm{R} 28$ & 0.649 & 0.091 & $5 \%$ & & \\
\hline $\mathrm{R} 29$ & 0.575 & 0.08 & $5 \%$ & & \\
\hline $\mathrm{R} 30$ & 0.565 & 0.079 & $5 \%$ & & \\
\hline R31 & 0.571 & 0.08 & $5 \%$ & \multirow{4}{*}{ safety } & \multirow{4}{*}{$18 \%$} \\
\hline R32 & 0.412 & 0.058 & $3 \%$ & & \\
\hline R33 & 0.649 & 0.091 & $5 \%$ & & \\
\hline R34 & 0.601 & 0.084 & $5 \%$ & & \\
\hline R35 & 0.362 & 0.051 & $3 \%$ & \multirow{5}{*}{ empathy } & \multirow{5}{*}{$23 \%$} \\
\hline R36 & 0.54 & 0.076 & $4 \%$ & & \\
\hline R37 & 0.73 & 0.102 & $6 \%$ & & \\
\hline R38 & 0.562 & 0.079 & $5 \%$ & & \\
\hline R39 & 0.611 & 0.086 & $5 \%$ & & \\
\hline
\end{tabular}

Source: Author's own elaboration, from the collected data and processed in the statistical program SPSS, V18.

Table 6: Component and score matrix.

With the identification of these variables, it is affirmed that there are variables (reliability and empathy) that affect the perception of quality and are more representative for medical tourists. Therefore, it is recommended that health service providers become more aware of these variables.

\section{Conclusion}

If a Service Company wishes to maintain an adequate level of competitiveness, must use analytical procedures and formal decisions to systematize and coordinate the administration, aimed at achieving maximum efficiency in its actions. Medical services companies operate in a dynamic and competitive environment and the quality of service is becoming a strong strategic advantage in winning customers. Nevertheless, the fact that many countries with poor health systems invest in this area is evidence that medical tourism is seen as a very important business opportunity [16].
It is also important to mention that customers are increasingly demanding, and not only seek price and quality, but also good service, a pleasant atmosphere, seeking comfort, personalized service, and quick service. With the increased knowledge on issues regarding brand image, value and quality of medical services; medical tourists have become more sophisticated and demanding in their choices [17]. For this reason, companies must carry out service planning activities, it is evident that the deficiencies begin when there is no research related to marketing, internal communication systems, and planning activities, this will identify needs, desires, preferences and customer perceptions.

The results obtained are representative and show high levels of validity and reliability for each evaluated variable, which exceeds 917. The results of the factorial analysis through the principal components extraction method, allowed determining if there is a correlation between the variables that affect the perception of service quality and 
that the variables of reliability and empathy are the most representative in the medical tourism environment.

The reliability that is related to the provision of the service in an accurate and careful manner, i.e., there are a breach in the provision of programmed services, so that the staff shows a lack of knowledge in the registry of the information of the users, there is a disinterest in the resolution of problems and there is no continuity and logical order in the attention.

On the other hand, the empathy that refers to individualized attention, easy access, good communications and understanding, i.e., that the doctor and the contact personnel know the name of their patient, since it is important that the client feel recognized by the staff who tends to him, that there is a registration system that allows having complete information of the patients and that the personnel is trained. The effects that can be observed not addressing these problems are client decrease, reduction in perceived quality and a decrease in the recommendation rate.

Finally, to improve the quality of services, first, we must be aware of the importance of providing a quality service, then quantitatively measure the quality levels perceived by the client, of which the positive and negative aspects of service are identified, enhance the positive aspects and decrease the negative aspects, and repeat this process constantly, always aspiring to a better result.

\section{References}

1. Gaines J, Lee CV (2019) Medical tourism. In Travel Medicine. Elsevier pp: 371-375.

2. Klímová B, Kuča K (2020) Medical tourism: Its research and implications for public health. Central European Journal of Public Health 28(3): 226-229.

3. Cronin JJ, Taylor SA (1994) SERVPERF versus SERVQUAL: reconciling performance-based and perceptions-minusexpectations measurement of service quality. Journal of marketing 58(1): 125-131.

4. Almomani RZQ, Al-Ghdabi RR, Hamdan KM (2020)
Patients' satisfaction of health service quality in public hospitals: A PubHosQual analysis. Manag Sci Lett (8): 1803-1812.

5. Myles PS (2020) More than just morbidity and mortality - quality of recovery and long-term functional recovery after surgery. Anaesthesia 75(S1): e143-150.

6. Zeithaml V, Parasuraman A (1988) Communication and Control Processes in the Delivery of Service Quality. Jornal of Marketing.

7. Crosby P (1998) Quality is free. The art of making quality certain. In: $11^{\text {th }}$ (Edn.), México.

8. Thompson I (2015) Satisfacción del cliente. PromoNegocios.net.

9. Medina, Rosgaby (2018) A satisfied customer is the best advertisement for your company. Branch digital magazine.

10. Kotler P, Armstrong G (2013) Fundamentos de Marketing. México: Pearson.

11. Donabedian A (1966) Evaluating the Quality of Medical Care. The Milbank Memorial Fund Quarterly. 83(4): 691729.

12. Kano N (1984) Calidad Atractiva y Calidad Obligatoria.

13. Zeithaml V, Parasuraman A (1988) Communication and Control Processes in the Delivery of Service Quality. Jornal of Marketing 52(2).

14. Grönroos C (1984) A service quality model and its marketing implications. European Journal of Marketing.

15. Kotler P (2006) Dirección de mercadotecnia. In: $8^{\text {th }}$ (Edn.), México: Pearson-Prentice Hall.

16. Çapar H, Aslan O (2020) Factors Affecting Destination Choice in Medical Tourism. Int J Travel Med Glob Heal 8(2): 80-88.

17. Cham TH, Cheng BL, Low MP, Cheok JBC (2020) Brand image as the competitive edge for hospitals in medical tourism. Eur Bus Rev 33(1). 